\title{
FISIOLOGÍA DE LAS GLÁNDULAS PARATIROIDES. DISFUNCIÓN Y PARÁMETROS FUNCIONALES DE LABORATORIO EN PARATIROIDES
}

\section{Physiology of de Parathyroid Glands. Disfunction and Functional Parameters of Paratyroid Laboratory}

\author{
Luis Francisco SANTIAGO-PEÑA \\ Complejo Asistencial Universitario de Zamora. Sección de Endocrinología y Nutrición. Zamora. España. \\ Correspondencia: lsantiago@saludcastillayleon.es
}

Fecha de recepción: 28 de septiembre de 2019

Fecha de aceptación: 23 de diciembre de 2019

Fecha de publicación: 26 de diciembre de 2019

Fecha de publicación del fascículo: 1 de septiembre de 2020

Conflicto de intereses: Los autores declaran no tener conflictos de intereses

Imágenes: Los autores declaran haber obtenido las imágenes con el permiso de los pacientes

Política de derechos y autoarchivo: se permite el autoarchivo de la versión post-print (SHERPA/RoMEO)

Licencia CC BY-NC-ND. Licencia Creative Commons Atribución-NoComercial-SinDerivar 4.0 Internacional

Universidad de Salamanca. Su comercialización está sujeta al permiso del editor

RESUMEN: El calcio y el fósforo están implicados en importantes funciones del organismo, tanto a nivel intracelular como extracelular. Por ello, deben existir mecanismos reguladores que mantengan las concentraciones de calcio y fósforo en sus intervalos de normalidad. El objetivo de este artículo es revisar la fisiología de la glándula paratiroides, así como el papel de la vitamina D y del factor de crecimiento de fibroblatos 23 (FGF 23) en el metabolismo fosfocálcico y también interpretar las alteraciones analíticas para el adecuado estudio de las patologías del metabolismo fosfocálcio.

PALABRAS CLAVE: glándulas paratiroides; hormona paratiroidea; calcitriol; factor de crecimiento de fibroblastos 23; alteraciones del metabolismo del Ca.

SUMMARY: Calcium and Phosphorus are involved in important functions of the organism, both intracellular and extracellular. Therefore, there must be regulatory mechanisms that maintain calcium and phosphorus concentrations at their normal intervals. The objective of this article is to review the physiology of the parathyroid gland, as well as the role of vitamin D and Fibroblast Growth Factor 23 (FGF 23) in phosphocalcic metabolism and also interpret analytical alterations for the proper study of pathologies of phosphocalcium metabolism.

KEYWORDS: parathyroid glands; parathyroid hormone; calcitriol; fibroblaste growth factor 23; calcium metabolism disorder. 


\section{FISIOLOGÍA DE LAS GLÁNDULAS PARATIROIDES. DISFUNCIÓN \\ Y PARÁMETROS FUNCIONALES DE LABORATORIO EN PARATIROIDES SANTIAGO-PEÑA L F}

\section{INTRODUCCIÓN}

La importancia de lo iones minerales (calcio, fósforo y magnesio) para la fisiología celular normal, así como para la integridad ósea, se refleja en los poderosos mecanismos de control endocrinos que han evolucionado para mantener sus concentraciones extracelulares dentro de límites relativamente pequeños.

El calcio (Ca) y el fósforo $(\mathrm{P})$ son los principales constituyentes del hueso, representando entre los dos el $65 \%$ del peso del hueso. Más de la mitad del magnesio $(\mathrm{Mg})$ corporal se encuentra en el hueso.

Las principales hormonas que intervienen en la homeostasis mineral, en el ser humano, son la hormona paratiroidea (PTH), las 1,25 dihidroxivitamina $\mathrm{D}\left(1,25(\mathrm{OH})_{2} \mathrm{D}_{3}\right.$ o calcitriol) y el factor 23 de crecimiento de los fibroblastos (FGF23).

En esta revisión, trataremos de conocer la fisiología del metabolismo mineral y de sus hormonas para tener una adecuada valoración de los parámetros de laboratorio y de las alteraciones clínicas relacionadas.

\section{BIOLOGÍA DEL METABOLISMO MINERAL}

El $99 \%$ del calcio corporal está en el tejido óseo, del cual 99 \% está cristalizado en la fase mineral (cristales de hidroxiapatita) y el $1 \%$ puede intercambiarse con el calcio extracelular.

Cerca del $50 \%$ del calcio total plasmático circula unido a proteínas, principalmente albúmina. El calcio libre es la fracción biológicamente activa y la que está bajo control hormonal.

El $85 \%$ del fosfato se encuentra en la fase mineral del hueso y el resto en forma inorgánica u orgánica en los espacios extracelulares e intracelulares. Solo el $12 \%$ del fosfato sérico se halla unido a proteínas.

El $50 \%$ del magnesio no está secuestrado en la fase mineral y puede intercambiarse libremente con otros iones del líquido extracelular. El
Mg sérico circula unido a proteínas en un tercio aproximadamente.

El Mg intracelular, al igual que el fosfato, es necesario para una gran variedad de funciones celulares (cofactor de reacciones enzimáticas de vía glucolítica, cinasa, fosfatasa, estabilizador de macromoléculas como ADN, ARN; activador de transportadores iónicos; metabolismo mitocondrial oxidativo).

\section{HORMONA PARATIROIDEA}

La hormona paratiroidea (PTH) es una proteína (84 aminoácidos) sintetizada y secretada en las células principales de las glándulas paratiroides.

Una vez sintetizada, la PTH es almacenada en vesículas y gránulos secretores en el interior de las células paratiroideas principales.

El principal regulador de la secreción de $\mathrm{PTH}$ es la concentración de Ca iónico en sangre.

En estado fisiológico estable, la relación entre el Ca iónico y la PTH se refleja como una curva dosis-respuesta sigmoidea inversa (Figura 1).

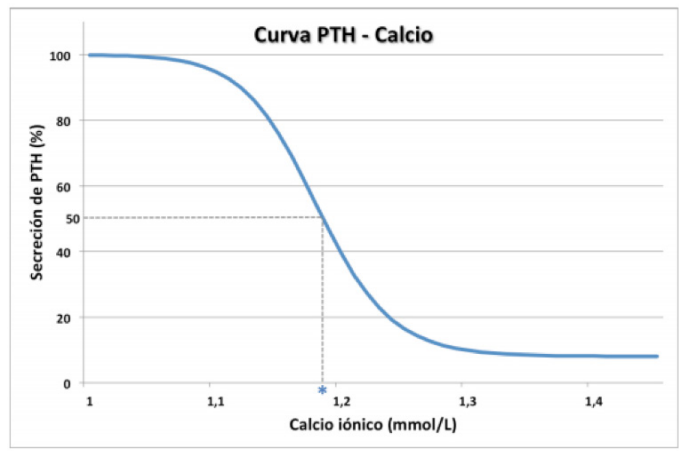

Figura 1. Relación sigmoidea inversa entre niveles de Ca iónico y máxima respuesta de PTH. Obtenida de Alejandro Castro Calvo: Valor de la PTH como predictor de la necesidad de tratamiento para la hipocalcemia post-tiroidectomía. (tesis doctoral en internet) Universidad Autónoma de Madrid, 2015. Recuperado en https://repositorio.uam.es/bitstream/ handle/10486/669528/castro_calvo_alejandro.pdf 


\section{FISIOLOGÍA DE LAS GLÁNDULAS PARATIROIDES. DISFUNCIÓN Y PARÁMETROS FUNCIONALES DE LABORATORIO EN PARATIROIDES SANTIAGO-PEÑA L F}

La célula paratiroidea responde al nivel de calcio iónico mediante el Receptor sensible al $\mathrm{Ca}$ (RSCa) de su superficie. Cuando el Ca iónico disminuye en suero se produce una inactivación del RSCa que da lugar, por segundos mensajeros intracelulares, a promover síntesis de $\mathrm{PTH}$ y a liberación de PTH de los gránulos y vesículas. Al contrario, cuando aumenta calcio iónico se produce activación del RSCa dando lugar a una disminución en la producción de PTH.

La PTH actúa en los órganos dianas a través del receptor PTH/PTHrP, presente en las membranas celulares de osteoblastos y riñón, fundamentalmente, pero también en otros tejidos.

Acciones de la PTH:

a) A nivel renal:

- Estimula la reabsorción de Ca a nivel del túbulo contorneado distal y túbulo colector (donde se produce la reabsorción del $30 \%$ de Ca iónico filtrado) activando los canales epiteliales de $\mathrm{Ca}$ (los receptores de potencial transitorio vaniloides tipo 5 (TPRV5, en inglés)), la calbindina-D28K, el cotransportador de Na-Ca (NCX1) y la bomba de calcio de membrana plasmática (PMCa1b, en inglés), tanto directa como indirectamente (por aumento síntesis de Calcitriol).

- Inhibición de la reabsorción de fosfato a nivel tubular por disminución de la Vmáx en el cotransporte de Na-P.

- Estimula la síntesis de Calcitriol en el túbulo proximal al inducir la transcripción del gen de la 1a-hidroxilasa de la 25-hidroxivitamina $\mathrm{D}[25(\mathrm{OH}) \mathrm{D}]$.

b) A nivel óseo: Los osteoclastos no tiene receptor de PTH. La PTH actúa sobre el osteblasto, induciendo la liberación de ligando RANK y factor estimulante de colonias de Osteoblastos (M-CSF, en inglés) y disminuyendo la producción de osteoprotegerina. Esto hace que se estimule la conversión del precursor de osteoclasto en osteclastos, que son los responsables de la resorción ósea en la matriz ósea. c) A nivel intestinal: La PTH actúa a nivel intestinal favoreciendo la absorción de Ca y $\mathrm{P}$ de la dieta a través del efecto directo de la $1,25(\mathrm{OH})_{2} \mathrm{D}_{3}$ en el enterocito (se verá en el apartado de la Vitamina D).

\section{VITAMINA D}

La vitamina $\mathrm{D}$ no es una vitamina verdadera. La fuente principal de vitamina $\mathrm{D}$ es por síntesis cutánea tras exposición solar. La incidencia de la radiación UV-B solar sobre la piel transforma el 7-deshidrocolesterol en provitamina $\mathrm{D}$ que, debido a su termolabilidad, se transforma, en la piel, en vitamina D. Esta pasa a la circulación, se une a la proteína transportadora de vitamina $\mathrm{D} y$ en el hígado, por acción de la 25-hidroxilasa, se transforma en 25-hidroxivitamina D (25OHD) o calcidiol, que tiene una vida media de 2-3 semanas.

La 25(OH)D se transforma, por acción de la 1a-hidroxilasa, en el túbulo contorneado proximal renal, en $1,25(\mathrm{OH})_{2} \mathrm{D}_{3}$ o Calcitriol, que tiene una vida media de 6-8 horas.

Al contrario que la 25-hidroxilasa, la 1a-hidroxilasa está muy regulada, siendo estimulada por la PTH y la hipofosfatemia e inhibida por el calcio y la FGF23.

El calcitriol realiza sus funciones biológicas por unión a receptor nucleares. El receptor de la vitamina $\mathrm{D}$ actúa formando un heterodímero con el receptor retinoide-X, uniéndose a elementos de ADN y captando coactivadores facilitando la transcripción de ADN a RNAm.

El calcitriol tiene también acciones no genómicas, como el rápido aumento de Ca intracelular, la activación de fosfolipasa $\mathrm{C}$ y la abertura de canales $\mathrm{de} \mathrm{Ca}$, que requieren un receptor nuclear intacto.

Acciones De LA 1,25(OH $)_{2} \mathrm{D}_{3}$

a) En el intestino: Aumenta la absorción de Ca, incrementado la expresión de receptores TRPV 6 en el polo luminal del enterocito, induciendo la síntesis de calbindina $9 \mathrm{~K}$ intestinal 


\section{FISIOLOGÍA DE LAS GLÁNDULAS PARATIROIDES. DISFUNCIÓN \\ Y PARÁMETROS FUNCIONALES DE LABORATORIO EN PARATIROIDES \\ SANTIAGO-PEÑA L F}

(transporte transcelular) e incrementando la expresión del la bomba de Ca-dependiente de ATP (PMCA1b) de la superficie antiluminal del enterocito.

b) En el hueso: Induce la síntesis de Osteocalcina. En individuos con balance negativo de calcio, promueve el aumento de pirofosfato, permitiendo la salida de Calcio del hueso a la circulación.

c) En el riñón: Aumenta la reabsorción de Ca en el túbulo contorneado distal y colector, induciendo la expresión de TRPV 5 y CalbindinaD28K.

d) En la célula paratiroidea: Disminuye la transcripción del gen de la PTH tanto in vivo como in vitro.

\section{FACTOR 23 DE CRECIMIENTO FIBROBLÁSTICO (FGF23) [3]}

El FGF23 es una proteína de 251 aminoácidos, sintetizada y secretada por las células óseas, fundamentalmente el osteoblasto. Ha sido identificado como el principal regulador del metabolismo del fósforo.

FGF23 se expresa también en miocardio, hígado, glándula tiroides y paratiroides, músculo esquelético e intestino

La acción biológica del FGF23 se realiza a través de receptores de membrana, denominados FGFR 1, 3 y 4 del receptor transmembrana $\beta$ glucoronidasa. Su acción a través del FGFR1 a nivel renal necesita de su correceptor Klotho.

Acciones biológicas de FGF23:

a) En el hueso: Aún no se ha evidenciado un efecto directo de FGF23 sobre el hueso, aunque en enfermedades como la osteomalacia y el raquitismo, sus valores en sangre estén elevados.

b) En el riñón: Disminuye la reabsorción tubular de fosfato a nivel del túbulo próxima, aumentando la excreción urinaria de $\mathrm{P}$, mediante inhibición de la expresión de los cotransportadores Na-P tipo II ( $\mathrm{Na} / \mathrm{P}$ IIa y $\mathrm{Na} / \mathrm{P}$ IIc). También disminuye los niveles de calcitriol por doble acción: inhibiendo la $1 \alpha$-hidroxilasa y estimulando la 24-hidroxilasa.

c) En la glándula paratiroidea: Disminuye la síntesis y secreción de PTH.

\section{REGULACIÓN DEL METABOLISMO MINERAL}

La cantidad de Ca y P ingerido con la dieta influye en la homeostasis de estos elementos.

Así una dieta pobre en Ca dará lugar a un aumento de PTH que actuará sobre el riñón favoreciendo la reabsorción de $\mathrm{Ca}$ (y disminuyendo la excreción urinaria de Ca), sobre el hueso favoreciendo la resorción ósea y sobre el enterocito aumentado la capacidad de absorción (mediada por calcitriol).

Una dieta rica en calcio inhibiría la secreción de PTH y la acción del calcitriol a nivel renal (disminuyendo reabsorción) y a nivel intestinal (disminuyendo absorción) y a nivel óseo no aumentando la resorción ósea.

Aunque la absorción intestinal de P y la liberación ósea de $\mathrm{P}$ son importantes determinantes de la carga de fósforo filtrada es el umbral renal de la reabsorción de fosfato en el túbulo proximal el factor más importante que determina la homeostasis de $\mathrm{P}$ [2].

\section{EVALUACIÓN DE LABORATORIO DEL METABOLISMO MINERAL}

Para evaluar adecuadamente el metabolismo mineral, se debería determinar en sangre: calcio, calcio iónico, P, Mg, PTH intacta, 25OHD y en orina, Ca y P. En la práctica diaria, se suele determinar Calcio total o Calcio total junto con Fosfato, y si están alterados, en un segundo paso se determinan el resto de los parámetros. 
FISIOLOGÍA DE LAS GLÁNDULAS PARATIROIDES. DISFUNCIÓN

Y PARÁMETROS FUNCIONALES DE LABORATORIO EN PARATIROIDES

SANTIAGO-PEÑA L F

Tabla 1. Situaciones clínicas en el estudio del metabolismo fosfocálcico.

\begin{tabular}{|c|c|c|c|c|c|}
\hline $\mathrm{Ca}^{++} / \mathrm{Ca}$ corregido & Fósfato & PTHi & 25OHD & $1,25(\mathrm{OH}) \mathrm{D}$ & situación clínica \\
\hline $\mathrm{N}$ & $\mathrm{N}$ & $\mathrm{N}$ & $\mathrm{N}$ & $\mathrm{N}$ & Normalidad \\
\hline $\mathrm{N}$ & $\mathrm{N}$ & Elevada & $\mathrm{N}$ & $\mathrm{N}$ & Hiper PTH $1^{\circ}$ normocalcémico \\
\hline $\mathrm{N}$ & $\mathrm{N}$ & Elevada & B & B & HiperPTH $\mathbf{2}^{\circ}$ \\
\hline Elevado & $\operatorname{Bajo}(\mathrm{N})$ & Elevada & $\mathrm{N} / \mathrm{B}$ & $\mathrm{N}$ & HiperPTH $1^{\mathbf{0}}$ \\
\hline Elevado & $\mathrm{N}$ & B & $\mathrm{N}$ & $\mathrm{N}$ & Hipercalcemia PTH no dependiente \\
\hline B & $\mathrm{N}$ & Elevada & $\mathrm{N}$ & $\mathrm{N}$ & PseudohipoPTH \\
\hline B & Elevado & $\mathrm{B}$ & $\mathrm{N}$ & $\mathrm{N}$ & НipoРТН $1^{\circ}$ \\
\hline B & B & Elevada & $\mathrm{N}$ & $\mathrm{MB}$ & Raquitismo I(déficit 1aOHasa) \\
\hline B & B & Elevada & $\mathrm{N}$ & Elevada & Raquitismo II (Fallo receptor vit D) \\
\hline $\mathrm{N}$ & MB & N/Elevada & $\mathrm{N}$ & N/B & Raquitismo hipofosfatémico \\
\hline $\mathrm{N}$ & MB & Elevada & $\mathrm{N}$ & B & Osteomalacia Oncogénica \\
\hline
\end{tabular}

N: normal; B: Bajo; MB: muy bajo; PTH: Paratirodismo. En negrita, se resaltan los patrones analíticos en los que las glándulas paratiroides son patológicas.

El Ca total debe ser siempre valorado, conociendo el nivel de albúmina o de proteinas totales, pues alteraciones de éstas influirán en su valor. De esta manera obtenemos el Ca corregido cuya fórmula es: Ca corregido $(\mathrm{mg} / \mathrm{dl})=$ Ca medido $(\mathrm{mg} /$ $\mathrm{dl})+[4-\text { Albúmina }(\mathrm{g} / \mathrm{dl})]^{*} 0,8$. (hay herramientas en la web que facilitan su cálculo). Si se sospecha patología, lo recomendable es medir Ca iónico.

La determinación conjunta de Ca iónico, fósfato, PTHi, 25OHD y 1,25(OH)D nos permite establecer unos patrones de alteración clínica que nos indicará si la enfermedad está en la glándula paratiroides o fuera de la paratiroides.

Estos patrones clínicos son los que se reflejan en la Tabla 1.

\section{CONCLUSIONES}

El conocimiento de las acciones biológicas de las hormonas (PTH, vitamina D, FGF23) implicadas en el metabolismo, así como el manejo renal, óseo e intestinal del Ca y del $\mathrm{P}$ resulta importante para la adecuada valoración de los parámetros analíticos que reflejan el metabolismo fosfocálcico tanto en situaciones fisiológicas como en aquellas patologías que directa o indirectamente afectan a los órganos en los que se secreta las hormonas anteriormente mencionadas.

\section{BIBLIOGRAFÍA}

1. Bringhurst FR, Demay MB,Kronenberg HM. Hormonas y alteraciones del metabolismo mineral. En Kronenber MD, Melmed S, Polonsky KS, Larsen PR editories. Williams Tratado de Endocrinologia Edicion 11. 2009 p. 305-40.

2. Hogan J, Goldfarb S. Regulation of calcium and phosphate balance [internet]. En Sterns RH, Lam AQ, Editors. Uptodate 2019. Disponible en: www. uptodate.com. Consultado el 04/09/2019.

3. Salanova Villanueva L, Sánchez González C, Sánchez Tomero JA, Aguilera A, Ortega Junco E. Bone mineral disorder in chronic kidney disease: Klotho and FGF23; cardiovascular implications. Nefrologia. 2016; 36(4):368-75. 